\title{
CHARACTERIZATION OF COAL SAMPLES FROM GODAVARI KANI DEPOSITS USING FOURIER TRANSFORM INFRARED SPECTROSCOPY
}

Manoj B., ${ }^{*}$ Chandrasekharan K.A.** \& Kunjomana A.G. ${ }^{* * *}$

\begin{abstract}
Coal is one of the most abundant organic fuels available in India. Understanding the properties of minerals and ash in coal will be helpful in providing a better knowledge of the factors that control their performance in furnaces. The conventional tool for the analysis of mineral content is X-ray diffraction (XRD) method. The capability of XRD for quantitative analysis is restricted to the minerals with good crystal structures. For the amorphous and low crystalline minerals, XRD can not provide accurate quantitative information. At the same time, even for minerals with a good crystal structure, XRD measurement is a time consuming technique. However, studies on minerals have suggested that FTIR spectroscopy is a superior alternative with respect to speed, accuracy and lower cost. FTIR technique has been used widely in the
\end{abstract}

* Corresponding author, Lecturer, PG Dept. of Physics, Christ College, Bangalore - 560 029, E-mail: manoj.b@christcollege.edu.

**. Dean of Science; Christ College, Bangalore - 560029.

*** Professor, PG Dept. of Physics, Christ College, Bangalore - 560029. 
study of coal, minerals, fly ash and rock. Fourier transform infrared (FIIR) spectra of sub bituminous coal samples, collected from a borehole located at Godavari kani deposit, Andhro Pradesh were recorded between 400 and $4000 \mathrm{~cm}^{-1}$. A comparative study of mineral content in coke sample imported from china is also performed using FTIR spectroscopy.

\section{Introduction}

Due to its origin, coal is a chemically and physically extremely complex and heterogeneous material, consisting of organic and inorganic constituents. The acceptance of coal for particular processes in industry depends critically on both components. The organic structure of coal can be regarded as consisting of heterogeneous aromatic structure, with aromaticity increasing from low rank, (lignite) to high rank (anthracite) coals [1]. The organic part of coal also contains sulphur, oxygen, and nitrogen in functional groups. Fourier transform infrared (FTIR) spectroscopy is a widely used analytical technique for determining the different functional groups in coal structure. This method, being able to reveal carbohydrogenated structure (aromatic and aliphatic) and hetero atomic functions (mainly oxygenated) as well as the presence of minerals, is currently one of the most powerful techniques for coal characterization and thus is of paramount importance in the various utilization procedures of coal. The use of low rank coals in industrial combustion may affect the performance of furnace by forming slag at the bottom of fumace, which in tum affect efficiency, and lead to costly maintenance. Further the effluent gas coming out of furnace may increase pollution in the atmosphere. Characterization and various demineralization techniques of coal have been done by various groups [2-6].

In the present work, FTIR spectra of sub bituminous coal sample collected from Godavari coal field, Andhra Pradesh, South India, were used to investigate the chemical structure of these semi ranked coals: The results were compared with that of the industrial coke imported from China. The study is restricted to the absorption bands within the range $4000 \mathrm{~cm}^{-1}$ to $400 \mathrm{~cm}^{-1}$ mainly because almost all minerals show absorption in this region.

\section{Experimental Procedure}

\section{1 Analysis of sample}

Three samples - Coal-1, Coal-2 and Coal-3 were handpicked from Singerini Coal mines of Godavari Coal deposit at a depth of about $10 \mathrm{~m}, 30 \mathrm{~m}, 60 \mathrm{~m}$ from the 
mine 8 incline. All these samples were kept open in air for 3 months at $60 \%$ humidity.

For analysis, about $20 \mathrm{~g}$ of the sample is crushed in to fine powder of about $5 \mu \mathrm{m}$ size. $2 \mathrm{mg}$ of the powdered sample was then mixed with $\mathrm{KBr}$ in the ratio $1: 200$ and ground for about 10 minutes. The grinding time and the sample to $\mathrm{KBr}$ ratio 1:200 were kept constant for all the samples under study to ensure uniformity. The mixture was then placed in a $13 \mathrm{~mm}$ diameter die cavity and pressed under high pressure. A portion of each sample was also made in to a polished block, according to the standard technique described by Bustin et al. [7]:

The spectra were recorded by using Paragon 500, Perkin - Elmer spectrophotometer in the region $4000-400 \mathrm{~cm}^{-1}$. This spectrometer has the resolution of $4 \mathrm{~cm}^{-1}$. A standard polystyrene film was used for calibration purposes. To obtain consistent records the FT.IR spectra were recorded in 16 scan mode. Kramers-Kronig transformation [8] was applied to each transmittance spectra.

\section{Result \& Discussion}

\subsection{FTIR Spectral Analysis of Godavari Kani Coal Samples}

FTIR spectra of coal samples collected from Godavari coal field by random sampling are shown in Fig. 1.

Coal - 1 : Sample collected from $10 \mathrm{~m}$ depth Coal - 2 : Sample collected from $30 \mathrm{~m}$ depth Coal - 3 : Sample collected from $60 \mathrm{~m}$ depth

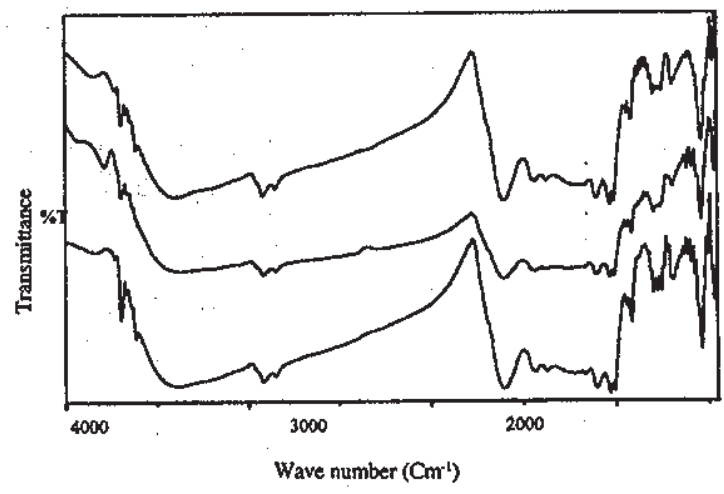

Fig. 1 :FTIR spectra of samples from Godavari Kani, Singerini coal mines 
Each absorption band in the spectra was analyzed for the intensity of transmission by Lambert-Beer law [9] and was categorized in to 5 spectral regions, very strong $(v . s)$, strong $(s)$, medium $(\mathrm{m})$, weak $(\mathrm{w})$ and very weak $(\mathrm{vw})$. Bands were assigned according to published articles $[2-5,1.0]$. The assignments of the prominent bands of IR absorption spectra of the three samples are given in table 1 .

Table 1, FTIR absorption frequencies, relative infensity estimate and their assignments

\begin{tabular}{|c|c|c|c|c|}
\hline \multirow{2}{*}{$\begin{array}{c}\text { Frequency } \\
\left(\mathrm{cm}^{-1}\right)\end{array}$} & & Intensify & - & \multirow[t]{2}{*}{ Assignments } \\
\hline & Coal-1 & Coal-2 & Coal-3 & \\
\hline 3700 & $m$ & $\mathrm{~m}$ & m & Absorption bands of Kaolinite \\
\hline 3670 & $\mathrm{~m}$ & - & $m$ & $\begin{array}{l}\mathrm{OH} \text {-in plane degenerated } \\
\text { vibration }\end{array}$ \\
\hline 3620 & $\mathbf{s}$ & - & s & $\begin{array}{l}\text { Inner O-H group of absorbed } \\
\text { water }\end{array}$ \\
\hline 3440 & vs & vs & vs & $\mathrm{OH}$-stretching (absorbed water) \\
\hline 2920 & vs & vs & vs & Aliphatic $\mathrm{CH}_{3}$ \\
\hline 2850 & vs & vs & vs & Aliphatic $\mathrm{CH}_{2}$ \\
\hline 1695 & vw & vw & vw & Carbonyl stretching \\
\hline 1605 & vs & vs & vs & Aromatic $\mathrm{C}=\mathrm{C}$ stretching \\
\hline 1500 & $w$ & $w$ & $w$ & Phenyl propane structure \\
\hline 1435 & vs & vs & vs & Methylene groups \\
\hline 1375 & vs & vs & vs & Methyl group \\
\hline 1165 & vs & vs & vs & C-O stretching of phenols \\
\hline 1105 & vs & vs: & vs & Si-O stretching \\
\hline 1030 & vs & ys & vs & Si-O stretching \\
\hline 1010 & vs & vs & vs & Si-O stretching \\
\hline 935 & m & $s$ & $m$ & OH out of plane bending \\
\hline 915 & $m$ & s & $m$ & - $\mathrm{CH}$ out of plane bending \\
\hline 795 & $w$ & $m$ & w & Quartz \\
\hline 775 & $w^{*}$ & $w$ & w & Quartz \\
\hline 756 & $w$ & - & w & $-\mathrm{CH}$ out of plane bending \\
\hline 695 & $m$ & $\mathrm{~m}$ & $\mathrm{~m}$ & $\mathrm{Si}-\mathrm{O}$ of $\mathrm{SiO}_{4}$ \\
\hline 630 & $v w$ & - & $\therefore$ & $\mathrm{Si}-\mathrm{O}$ of $\mathrm{SiO}_{4}$ \\
\hline 615 & $\mathrm{vw}$ & w & - & $\mathrm{Al}-\mathrm{OH}$ \\
\hline 595 & vw & $w$ & - & Form of Fe-O \\
\hline 575 & $w$ & - & vw & Form of $\mathrm{Fe}-\mathrm{O}$ \\
\hline 540 & s & s & $m$ & $\mathrm{Si}-\mathrm{O}-\mathrm{Al}^{\mathrm{N}}$ \\
\hline 495 & $w$ & w & w & Si-O-Alv \\
\hline 470 & $w$ & $w$ & w & $\mathrm{Si}-\mathrm{O}-\mathrm{Si}$ \\
\hline
\end{tabular}

$\mathrm{w}=$ very weak; $\mathrm{w}=$ weak; $\mathrm{m}=$ medium, $\mathrm{s}=$ strong; $\mathrm{vs}=$ very strong 
From Table: 1 it is seen that all the samples show weak absorption bands at $3700 \mathrm{~cm}^{-1}$. This is due to clay minerals present in the sample and is in the form of Kaolinite structure. The same result is reported by Venkatachalapathy et al. [1.1] on Neyveli lignite samples.

It is seen from Fig. 1 that the samples have more or less similar broad characteristic absorption bands. All the absorption bands are unresolved indicating that the material constituents have either large particle size or contain polymeric units. There is a broad and strong band observed in all the samples at $3440 \mathrm{~cm}^{-1}$ which can be attributed to hydroxyl stretching vibrations. This is well reflected from the observations of Osawa and Shih [12], Subkowiak et al. [13] and Chomnanti et al. [4] in the case of coal, oil shale and lignite samples. The absence of the band at $3030 \mathrm{~cm}^{-1}$ which is characteristic of $-\mathrm{CH}$ groups in the entire coal sample shows that they probably contain phenyl propane structures. It is also indicative of the fact that the aromatic condensation has not set in, a clear indication of early stage of formation of wood peat to coal stage. All these samples show remarkable similarity with wood peat spectrum. This is reported by Venkatachalapathy ef al. [1 1] in the case of Newveli lignite. Sharp intense bands observed at 2920 and $2850 \mathrm{~cm}^{-1}$ in all the samples can be attributed to the presence of valency oscillations of $\mathrm{CH}_{3}$ and $\mathrm{CH}_{2}$ aliphatic groups. Of these $2850 \mathrm{~cm}^{-1}$ band can be attributed to methoxy groups present in the samples. Chomnanti et al. [4] observed similar sharp bands at 2920 and $2850 \mathrm{~cm}^{-1}$ in the case of tertiary lignite. The sharpness of the bands in the studied samples indicates that the probable age of the coal as belonging to tertiary formations. Fujii et al. [5] calculated the specific extinction coefficients $(\mathrm{K})$ of the absorption bands at 3030, 2920 and $1605 \mathrm{~cm}^{-1}$ of twelve Japanese coal samples from lignite to anthracite. These bands arise due to aromatic- $\mathrm{CH}$, aliphatic$\mathrm{CH}_{3}$ and $\mathrm{C}=\mathrm{C}$ aromatic groups respectively. The intensity of the bands directly gives the percentage of carbon content in the sample. The intensity increases gradually as coal rank increased up to $86.2 \%$ carbon and then decreases with further increase of the coal rank. In very low rank coals the intensity of $2920 \mathrm{~cm}^{-1}$ is found to be very small due to the fact that the proportion of the aliphatic $-\mathrm{CH}_{3}$ hydrogen is substituted by hydroxyl groups.

Weak broad band at $1695 \mathrm{~cm}^{-1}$ and strong prominent band at $1605 \mathrm{~cm}^{-1}$ observed in all the samples can be attributed to carboxyl and $\mathrm{C}=\mathrm{C}$ stretching respectively. Starsinic et al. [14] assigned the band at $1695 \mathrm{~cm}^{-1}$ to carboxyl groups, possibly Ketones. Supaluknari et al. [15] observed the bands at 1695 and $1605 \mathrm{~cm}^{-1}$ in the case of brown coals and oxygen rich sub bituminous coals, while in higher rank coals with a low oxygen content the absorption at $1695 \mathrm{~cm}^{-1}$ appears as a shoulder on the $1605 \mathrm{~cm}^{-1}$ band. The strong band near $1695 \mathrm{~cm}^{-1}$ is attributed predominantly to carboxylic acid and a relatively weak band at $1670 \mathrm{~cm}^{-1}$ is assigned to ketonic 
structures. They also observed that the total absorbance of all the carboxyl bands for the brown coal sample is greater than those for the higher rank coal samples. The Brown coal with higher oxygen content $(O / C=0.26)$ contain less amount of carboxyl group (both as acids and esters) and has lower intensity for $1695 \mathrm{~cm}^{-1}$ band than brown coal with low oxygen content.

It is clear that the samples having higher oxygen content have low intensity absorption band at $1695 \mathrm{~cm}^{-1}$. while the samples having low oxygen content show well resolved and intense band at $1695 \mathrm{~cm}^{-1}$. The presence of weak absorption band in the spectra shows that coal samples are rich in oxygen content. Such a result is in conformity with the observations of Supaluknari et al. [15] in the case of oxygen rich Australian Brown coal.

A very pronounced absorption band at $1605 \mathrm{~cm}^{-1}$ is present in all the coal samples, due to $\mathrm{C}=\mathrm{C}$ aromatic stretching. Brown [2] observed prominent band at 1605 $\mathrm{cm}^{-1}$ in the case of coal samples and suggested that this band can arise due to aromatic ether linkages. Motterra and Low [10] found the band at $1605 \mathrm{~cm}^{-1}$ in the case of wood charcoal and assigned it to aromatic $\mathrm{C}=\mathrm{C}$ vibrations. Low and Glass [5] made elaborate discussion of $1605 \mathrm{~cm}^{-1}$ band of coal. They assigned the band in case of in low rank coals and chars which have been formed at relatively low temperature, to aromatic ring stretch of small, discrete aromatic entities. They also suggested that the oxygen containing structure may or may not be involved in the formation of $1605 \mathrm{~cm}^{-1}$ band.

On the basis of above observations the band observed at $1605 \mathrm{~cm}^{-1}$ can be attributed to aromatic ring stretch of small, discrete aromatic groups present in Godavari samples. In addition to the above absorption band observed of 1605 $\mathrm{cm}^{-1}$, broad bands at $1435,1375,1165,1105 \mathrm{~cm}^{-1}$ and shoulder band at 1030 $\mathrm{cm}:$ ' has been observed in all the samples. Unresolved plateau like bands observed in this region shows that the coal samples constitute complex polymeric materials.

Chomnanti et al. [4] observed similar type of bands in the case of lignite sample. They assigned the band at $1435 \mathrm{~cm}^{-1}$ to methylene and methyl deformation vibrations, $1370 \mathrm{~cm}^{-1}$ to methyl deformation vibrations and a plateau of absorption around 1100 to $1300 \mathrm{~cm}^{-1}$ to C.O vibrations. Buravas et al. [3] studied the infrared spectra of tertiary lignite and woody peat. They observed the bands at 1500, 1435, $1410,1375 \mathrm{~cm}^{-1}$ and to a lesser extent around $1200 \mathrm{~cm}^{-1}$, where lignite shows a plateau of more or less unresolved absorption bands. Pleistocene lignite and woody peat showed absorption bands at 1500,1435 and $1410 \mathrm{~cm}^{-1}$. Pleistocene-Miocene $(66-74 \% \mathrm{C})$ lignite showed a peak at $1500 \mathrm{~cm}^{-1}$ and broad absorption throughout $1450-1410 \mathrm{~cm}^{-1}$. In the case of coal sample, marked absorption was observed on only at $1500 \mathrm{~cm}^{-1}$. The band at $1500 \mathrm{~cm}^{-1}$ is due to benzene rings and this 
disappears in older lignite \& coal [11]. This is probably due to the increasing substitution of the aromatic rings. From these observations they concluded that the absorption band at $1500 \mathrm{~cm}^{-1}$ can be associated with the presence of phenyl propane type structures and it can be used in the dating of solid fuels. They assigned the band at $1450.1410 \mathrm{~cm}^{-1}$ to deformation vibrations of methylene groups and the band at $1375 \mathrm{~cm}^{-1}$ to the methyl groups.

Kister et al. [16] found weak broad residual absorption band between 1200 to $1300 \mathrm{~cm}^{-1}$ in the case of low rank Gardanne coal and assigned the band to C-O bonds, as in phenols or ethers. Zelei ef al. [17] studied the infrared spectra of Mesburg, GDR brown coals and assigned, the bands at $1435 \mathrm{~cm}^{-1}$ to deformation vibrations of $\mathrm{CH}_{3}$ group, $1375 \mathrm{~cm}^{-1}$ band to out of plane bending mode of $\mathrm{CH}_{2}$ group and deformation vibrations of $\mathrm{CH}_{3}$ group, $1375 \mathrm{~cm}^{-1}$ band to out of plane bending mode of $\mathrm{CH}_{2}$ group and deformation vibrations of $\mathrm{CH}_{3}$ group, $1270 \mathrm{~cm}^{-1}$ band to antisymmetric $(\mathrm{C}-\mathrm{O}-\mathrm{C})$ stretching in aliphatic esters, $1165 \mathrm{~cm}^{-1}$ band to C-O stretching modes and 1105 to $1010 \mathrm{~cm}^{-1}$ band to $\mathrm{Si}-\mathrm{O}$.Si bands in silicate minerals. Cannon et al. [18] found the IR bands in the case of Rawhide sub bituminous coal and Texas lignite sample at $1165 \mathrm{~cm}^{-1}$ and assigned the band to C-O stretching of phenolic hydroxyl groups. Olson et al. [19] found the band at $1030 \mathrm{~cm}^{-1}$ in the Beulah lignite sample and this band was assigned to the clay absorption.

From the above observations the weak broad bands observed at 1435 and 1375 $\mathrm{cm}^{-1}$ can be assigned to stretching modes of methylene and methyl groups present in the samples. The broad band observed at $1165 \mathrm{~cm}^{-1}, 1.105 \mathrm{~cm}^{-1}$ and $1030 \mathrm{~cm}^{-1}$ can be attributed to $\mathrm{C}-\mathrm{O}$ stretching of phenolic hydroxyl groups and trace amount of silicate minerals associated with the lignite samples respectively. The plateau like unresolved strong absorption region af $1165 \mathrm{~cm}^{-1}$ indicates the presence of $\mathrm{C}-\mathrm{O}$ stretching of phenolic hydroxyl groups and the complex nature of the polymeric material present in the samples.

A close scrutiny of the IR spectra reveals that the coal and woody peat shows a distinct though weak absorption band at $1500 \mathrm{~cm}^{-1}[3,11]$. This band indicates the presence of benzene rings in phenyl propane type structures and also indicates that these samples belong to Pleistocene-Miocene age. The present samples show a weak peak at $1500 \mathrm{~cm}^{-1}$ and can be safely assigned to Pleistocene-Miocene period on the lines suggested by Venkatachalapathy [ [ 1 1] and Buravas et al. [3].

Sobkowiak et al. [1] reported that sub bituminous coal samples have large absoptivities for different aliphatic-CH bonds, the highest being most likely for$\mathrm{CH}$ bonds in long chain methylene structure. They also reported that the absoptivities for aromatic $-\mathrm{CH}$ bonds is very small. 
In the present study, sample shows very strong absorption at $2920 \mathrm{~cm}^{-1}$ and $2850 \mathrm{~cm}^{-1}$ which is assigned for aliphatic $-\mathrm{CH}_{3}$ and $-\mathrm{CH}_{2}$ groups respectively and weak absorption bands in the region $915 \mathrm{~cm}^{-1} \& 756 \mathrm{~cm}^{-1}$ is due to aromatic-CH out of plane structure [1]. From this information we can conclude that the sample is moderately ranked sub bituminous coal.

Maria et al. [2i] assigned the band at $3440 \mathrm{~cm}^{-1}$ for $-\mathrm{OH}$ stretching (absorbed water) and $400 \mathrm{~cm}^{-1}-600 \mathrm{~cm}^{-1}$ for silicate and clay minerals for low rank coals.

From the above information it is inferred that the Godavari kani coal samples constitute high moisture content and more of clay minerals with low carbon content. This indicates that they are low rank sub bituminous coal. Using this coal for industrial purpose requires cleaning. The formation of this coal has taken place during Pleistocene-Miocene period.

\section{FTIR Analysis of Coke}

The coke sample in the present analysis is an imported Chinese coal for the use of a thermal power plant in Karnataka. The sample was exposed to a temperature of $30^{\circ} \mathrm{C}$ and $60 \%$ humidity for about 3 months. FTIR of this sample also recorded as per the procedure mentioned above. The wave number vs transmittance IR spectrum is shown in Fig. 2

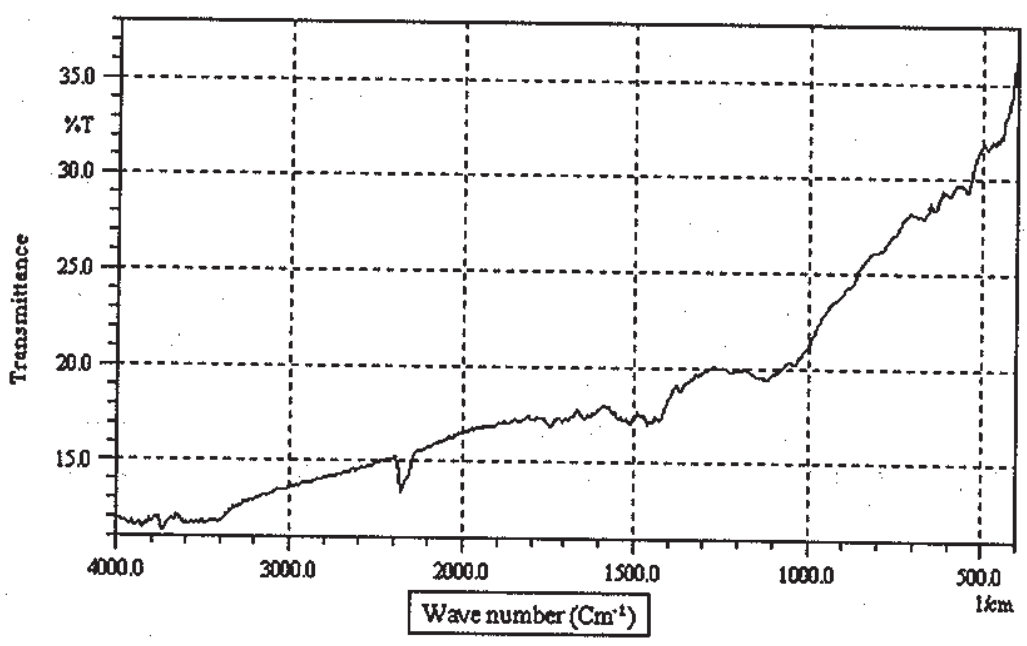

Fig. 2 : FTIR of Coke sample 
The spectrum is analyzed by Lambert-Beer law [9] for intensity comparison as mentioned above. Bands are assigned according to published article [2-10,20].

Table 2: FTIR absorption frequencies, relative intensity estimate and assignments of coke sample.

\begin{tabular}{|c|c|l|}
\hline Frequency $\left(\mathbf{c m}^{-1}\right)$ & Intensity & \multicolumn{1}{|c|}{ Assignments } \\
\hline 3390 & w & $\mathrm{OH}_{\text {stretching of absorbed water }}$ \\
2921 & $\mathrm{w}$ & Aliphatic $\mathrm{CH}_{3}$ \\
1435 & w & $\mathrm{CaCO}_{3}$ \\
1110 & m & carboxyl stretching \\
1030 & s & Si-O stretching \\
874 & w & Si-O Al \\
797 & w & Aromatic- $\mathrm{CH}$ out of plane bending \\
536 & w & Fe-O Stretching \\
472 & w & Fe-S Stretching \\
\hline
\end{tabular}

$\mathrm{w}=$ weak; $\mathrm{m}=$ medium, $\mathrm{s}=$ strong

From Fig. 2 it is observed that the pyrolysis has changed the structure of coal. When heating coal, the structural collapse of the minerals have taken place and the water molecules are removed. At $150^{\circ} \mathrm{C}$ the absorbed water molecules gets evaporated out, which is well reflected from the absence of $3400 \mathrm{~cm}^{-1}$ band. At $450^{\circ} \mathrm{C}$ the inner hydroxyl water molecules are removed which can be observed from the reduction of intensity of $3700 \mathrm{~cm}^{-1}$ band. At $650^{\circ} \mathrm{C}$ the clay structure gets destructed which reflects that triplet band at $1100 \mathrm{~cm}^{-1}$ is reduced to singlet. The above features indicate that, during pyrolysis, when the coal samples were heated to above $800^{\circ} \mathrm{C}$ for making coking coals, mineral structure is destructed and inter layer water is removed. It is well reflected from the IR spectrum of the coke sample. The well absorption bands at $1430 \mathrm{~cm}^{-1}$ along with $875 \mathrm{~cm}^{-1}$ arises due to residual clay minerals along with carbonate minerals found in the coking coal sample [20].

\section{Conclusion}

FTIR analysis of Godavari kani coal shows the presence of aliphatic $\mathrm{CH}_{2}, \mathrm{CH}_{3}$ structures along with aromatic $\mathrm{C}=\mathrm{C}$ stretching. High moisture and clay minerals content with low carbon content reveals that they are low rank sub bituminous coals. Coal samples show high amount of clay content which necessitates cleaning for industrial applications. The absence of the band at $3030 \mathrm{~cm}^{-1}$ which is characteristic of aromatic - $\mathrm{CH}$ bond in the entire coal sample shows that they 
contain phenyl propane structures. If is also indicative of the fact that the aromatic condensation has not set in, a clear indication of early stage of formation of wood peat to coal stage. The presence of weak band at $1500 \mathrm{~cm}^{-1}$ show that the aromatization of sample is not completed after formation and preferably assigned to Pleistocene-Miocene period. The absence of minerals, clay and water in coke sample indicates that, it can be used as a better fuel in furnace than coal for better calorific value and less environmental pollution.

\section{References}

1. Sobkowiak M, Painter P C. Fuel, 71, 1105 (1992).

2. Brown J.K, J. Chem. Soc. 747, (1950).

3. Buravas S, Gaines A F, Hasadsri T, Prasertwitayakh A and Mrs Sucharitakul, Fuel 49, 180 (1970).

4. Chomnanti S, Deemak P, Gaines A F, Kasomson K, Keowkamnerd K, Lowidhya V, Pomilying C, Mrs. Sucharitakul N, Witsuksomba VV and Wiroyamon W, Fuel 49, 180 (1970).

5. Fujii S, Osawa $Y$ and Sugimura H, Fuel $49,68(1970)$

6. Low M J D and Glass A S, Spectrosc. Lett. 22 (4), 417 (1989).

7. Bustin R M, Cameron A, 'Coal Petrology, Its Principles, Methods and Applications', Geological Association of Conada, Short Course Notes, 2nd Edn, (1985).

8. Hawrane J P, Neelakantan P, Young, R.P. Spectrochim.Acta, Part A, 32, 85 (1976).

9. Solomon P R, Carangelo R M and Zubkova Fuel, 67, 949, (1988).

10. Morterra C and Low M J D, Spectrosc. Lett. 1.5 (9), 689 (1982).

11. Venkatachalapathy $R$ and Ramaswamy K, Asian Chemistry Letters, 3, 160-166 (1999).

12. Osawa $Y$ and Shih J W, Fuel 50, 53 (1971):

13. Sobkowiok M, Reisser E, Given P and Pointer P, Fuel 63, 1245 (1984).

14. Starsinic M, Michael Y, Otake, Yoshinobu,. Walker P L. Jr Painter and Paul C, Fuel 63,1002 (1984).

15. Supaluknari S, Larkins F P, Redlich R and Jackson W R, Fuel process. Technol. 18,147 (1988).

16. Jacky Kister, Michel Guiliano, Gilberr mille, and Henri Dar Fuel, 67, 1076 (1998).

17. Landais $P$, and Rochdi A, Zelei. Energy Fuels, 4, 290 (1990).

18. Traverse A; Kolvoord R W, and Cannon. Science, 159, 302 (1968).

19. Olson Energy \& Fuels 21, 341 (1988).

20. Das T K Fuel, 80,489 (2001).

21. Maria Mastalerz, Max Bustin, R.74, 14,536 (1995). 